Elisabeth Vollers-Sauer · Prosa des Lebensweges 


\section{Elisabeth Vollers-Sauer}

\section{Prosa des Lebensweges}

Literarische Konfigurationen selbstbiographischen Erzählens am Ende des 18. und 19. Jahrhunderts

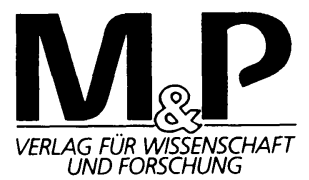


Danken möchte ich dem Deutschen Akademischen Austauschdienst, der das Entstehen dieser Arbeit durch ein Stipendium gefordert hat.

Die Deutsche Bibliothek - CIP-Einheitsaufnahme

\section{Vollers-Sauer, Elisabeth:}

Prosa des Lebensweges : literarische Konfigurationen selbstbiographischen Erzählens am Ende des 18. und 19.

Jahrhunderts / Elisabeth Vollers-Sauer. - Stuttgart : $M$ und $P$, Verl. für Wiss. und Forschung, 1993

(M-und-P-Schriftenreihe für Wissenschaft und Forschung)

Zugl.: Hannover, Univ., Diss., 1992

ISBN 978-3-476-45029-6

ISBN 978-3-476-45029-6

ISBN 978-3-476-04187-6 (eBook)

DOI 10.1007/978-3-476-04187-6

Dieses Werk ist einschließlich aller seiner Teile geschützt. Jede Verwertung außerhalb der engen Grenzen des Urheberrechtsgesetzes ist ohne Zustimmung des Verlages unzulässig und strafbar., Das gilt insbesondere für Vervielfältigungen, Übersetzungen, Mikroverfilmungen und Einspeicherung in elektronischen Systemen.

M \& $\mathbf{P}$ Verlag für Wissenschaft und Forschung ein Verlag der J. B.Metzlerschen Verlagsbuchhandlung und Carl Ernst Poeschel Verlag GmbH in Stuttgart

(c) 1993 Springer-Verlag GmbH Deutschland

Ursprünglich erschienen bei J. B. Metzlersche Verlagsbuchhandlung und Carl Ernst Poeschel Verlag GmbH in Stuttgart 1993 
"Es war vor einiger Zeit Mode, und ist es vielleicht noch, auf die Titel der Romane zu setzen: eine wahre Geschichte. Das ist nun eine kleine unschuldige Betrügerei, aber da $B$ man auf manchen neueren $\mathrm{Ge}$ schichtsbüchern die Worte: ein Roman wegläßt, das ist keine so unschuldige."

Georg Christoph Lichtenberg 


\section{Inhaltsverzeichnis}

Einleitung

I Wahrhafte Geschichten und natürliche Abenteuer:

Selbstbiographie und Roman im 18. Jahrhundert 16

1. Wahre Geschichten als Romane des Lebens,

Original und Kopie

1.1 Die literarische Komposition im Dienste der

Wahrscheinlichkeit $\quad 26$

1.2 Das 'Wahre' und das 'Wirkliche' in der Theorie des Romans 30

1.3 Poetische Wahrscheinlichkeit 39

1.4 Herder: Schrift als Abdruck der Seele 44

2. Idyllische Erzählung und Geisterkunde:

Die verweigerte Aufklärung 53

$2.1 \quad$ Von der Idylle zur Dorfgeschichte 56

$2.2 \quad$ "Henrich Stillings Jugend" - Eine wahrhafte Geschichte? 59

2.3 Stilling in "psychologischer Rücksicht" 65

3. "Anton Reiser" - Erfahrung auf den Begriff gebracht 67

3.1 Erinnern-Machen: Einsames Denken 71

3.2 Sprache - Quelle des Denkens und Licht der Seele 78

4. Natürliches Schreiben und das Abenteuer der Autorschaft 84

4.1 Ulrich Bräkers Wanderungen und Peter Proschs Schicksal 84

4.2 Pikareskes Erzählen oder natürliche Prosa?

5. Die (schlechten) Dinge, wie sie sind:

Selbstbiographie als Anti-Literatur

6. Idylle, Roman und Abenteuer. Ein Resümee 107

Exkurs: Idyllische Fiktionen $\quad 110$

Exkurs: Moritz und das 'Schöne' 115

7. Fabeln der Literaturgeschichte: Literar-Historiographie zur Autobiographie des 18. Jahrhunderts 
1. Erlebtes und erdichtetes Leben. Die Ausnahme Fontane

1.1 Roman oder "Reportertum"

1.2 Das 'Anekdotische ' und die Detailmalerei `als literarische Darstellungsverfahren

2. Ton der Städte und der Menschen - Sprechgraphie im autobiographischen Roman

2.1 Zitat einer Lebensform, Sprechphysiognomik

2.2 Poesie versus Prosa

2.3 Poetische Erinnerungsräume und Prosa des Streits

2.4 Uneigentliches und eigentliches Sprechen

2.5 Roman der Kindheit

3. Literarische Typik und Ironie in Fontanes

"Von Zwanzig bis Dreißig"

Exkurs: "Von Zwanzig bis Dreißig" als Historiographie

3.1 Ironische Distanz

3.2. Der Bourgeois und der Bankrotteur

3.3 Lebertran und Revolution

4. Resümee 